\title{
EFFECT OF ZN CONCENTRATION ON STRUCTURAL AND OPTICAL PROPRIETIES OF ZNO THIN FILMS DEPOSITED BY SPRAY PYROLYSIS
}

\author{
Z.Yamlahi Alami1,*,M. Salem2, M. Gaidi2,3,J.Elkhamkhami1 \\ ${ }^{1}$ laboratoire de la matière condensée, dept .de physique, faculté de sciences Avenue de \\ Sebta, Mhannech I 93002 - Tétouan - Maroc \\ ${ }^{2}$ Laboratoire de Photovoltaïque Centre de Recherches et des Technologies de l'Energie, \\ Technopole de Borj-Cédria, BP 95, 2050 Hammam-Lif, Tunisia. \\ ${ }^{3}$ Department of Applied Physics, University of Sharjah, P.O. Box 27272, Sharjah, United \\ Arab Emirates
}

\begin{abstract}
$\mathrm{ZnO}$ thin film were deposited by spray pyrolysis on glass substrates, using zinc nitrate as precursor with different molar concentrations varying from 0.05M to $0.2 \mathrm{M}$. To study the structural proprieties of the film, the different technique was used as the X-ray diffraction, atomic force microscopy (AFM), Raman scattering, and FTIR. The optical properties were explored by transmission, reflectivity and Photoluminescence techniques. The $\mathrm{ZnO}$ thin films obtained in this paper are polycrystallines, the grain size increases when the molar concentration of Zn precursor was increasing. The films are transparent in visible region, this transmission values decreases when the molar concentration increase caused by the increasing of surface roughness
\end{abstract}

\section{KEYWORDS:}

ZnO thin films; spray pyrolysis; roughness.

\section{INTRODUCTION}

The increasing demand for energy made the solar cells as a new source of energy [1,2] for replace the conventional sources. However, despite the concentrated efforts to develop the PV systems, the high cost of the generated electricity prevents that PV systems are more widely spread, to reduce these cost, efforts to improve efficiency and the searches was concentrating on cheaper materials and structures are undertaken .Thin film nanostructure is an attractive solution due to their unique properties.

Zinc oxide $(\mathrm{ZnO})[3]$ is one of the most extensively studied materials as an alternative photo anode to $\mathrm{TiO}_{2}[4] . \mathrm{ZnO}$ thin film has high transparency[5], piezoelectricity[6], room-temperature ferromagnetism[7], and huge magneto-optic[8] effect, it can be grown into many different nanoscale forms, thus allowing various novel devices to be achieved, also doping can improved some proprieties of $\mathrm{ZnO}$ [9], like conductivity which may change at will from metallic to insulting (including n-type and p-type conductivity. It has wide band gap energy of $3.37 \mathrm{eV}$, high 
exciton binding energy of $60 \mathrm{meV}$, a wide range resistivity, high electron Hall mobility (200 $\mathrm{cm} 2$.V.s ${ }^{-1}$ ) and high transparency at room temperature.

Some techniques was used to fabricate the $\mathrm{ZnO}$ thin film such as magnetron sputtering[10] spray plasma [11], sol gel spin coating[12] , pulsed laser deposition[13], metal-organic chemical vapor deposition and spray pyrolysis[5].

Spray pyrolysis is a versatile technique for deposition of metal oxides because of its cheapness and easy process control which gives the possibility of obtaining films with the required properties for different applications [5].

Different authors reported on the preparation of $\mathrm{ZnO}$ thin films by spray technique. In fact, $\mathrm{E}$. Bacaksiz et al. [14] prepared $\mathrm{ZnO}$ thin film starting with different solution precursors such as zinc chloride, zinc acetate and zinc nitrate, at $0.1 \mathrm{M}$ concentration on glass substrate and at $550^{\circ} \mathrm{C}$. It was observed that the nature of precursor affected the structural and optical proprieties of $\mathrm{ZnO}$ thin films. The higher value of transmittance was observed in $\mathrm{ZnO}$ thin films prepared with zinc nitrate precursors. Mazabala Banto et al [5] studied the effect of precursor concentration on structural, morphological and opto-electric properties of $\mathrm{ZnO}$ thin films starting by $\mathrm{ZnCl} 2$ dissolved in ethanol and deionized water with different molar concentrations increasing from $0.05 \mathrm{M}$ to $0.2 \mathrm{M}$ on glass substrate at $400^{\circ} \mathrm{C}$ and annealing or $5 \mathrm{~h}$,in air at $500^{\circ} \mathrm{C}$. In this work it was shown that the molarity of precursors affected the properties of $\mathrm{ZnO}$ thin film. The film present high transmission (95\%) at molar concentration 0.05M. E.U. Masumdar et al. [15] studied the effect of molarity on structural and opto-electric properties of $\mathrm{ZnO}$ thin films elaborated by using a precursor solution of zinc acetate in a mixed solvent of $75 \%$ methanol and $25 \%$ distilled water. The films were grow with different molar concentration varied from $0.1 \mathrm{M}$ to $0.75 \mathrm{M}$ on glass substrate and $450^{\circ} \mathrm{C}$, the average transmission of the films varied from $75 \%$ to $88 \%$.

The main purpose of this work is to obtain $\mathrm{ZnO}$ film with suitable proprieties for PV cells to can be used as a transparent conductive oxide (TCO) thin film, to reduce the losses during photovoltaic conversion [28].

In this study, the $\mathrm{ZnO}$ films deposited on the glass substrate was fabricated by zinc nitrate by varying molar concentration from $0.05 \mathrm{M}$ to $0.2 \mathrm{M}$. To reduce the fabrication cost, the $\mathrm{ZnO}$ thin film was prepared without annealing temperature, so we could obtain high transparent, good morphology and high quality of the crystal.

\section{EXPERIMENTAL DETAILS}

\subsection{Materials and preparation}

$\mathrm{ZnO}$ thin films were prepared by spray pyrolysis process from a solution with different molar concentrations of $\mathrm{Zn}\left(\mathrm{NO}_{3}\right)_{2}, 6 \mathrm{H}_{2} \mathrm{O}$ precursor $(0.05 \mathrm{M}, 0.1 \mathrm{M}, 0.15 \mathrm{M}$ and $0.2 \mathrm{M})$ in $25 \mathrm{ml}$ of deionized water. The spray system used in this work was fully described and schematically presented in [16]. The $\mathrm{Zn}\left(\mathrm{NO}_{3}\right)_{2}, 6 \mathrm{H}_{2} \mathrm{O}$ solution was sprayed with a solution spray rates of 2 $\mathrm{ml} / \mathrm{min}$ onto a preheated glass substrate at $500^{\circ} \mathrm{C}$ during $10 \mathrm{~min}$, using compressed air as a carrier gas. The nozzle to substrate distance was about $45 \mathrm{~cm}$. The obtained $\mathrm{ZnO}$ thin Films are transparent, exhibiting a good adherence to the substrate surfaces. 


\subsection{Measurements}

The structural characterization was carried out by X-ray diffraction (XRD) technique using a Bruker D 8 advance X-ray diffractometer with $\mathrm{CuK}_{\alpha}\left(\mathrm{k}=1.5418^{\circ} \mathrm{A}\right)$ radiation for $2 \theta$ values in the range of $25-60^{\circ}$.Film surface morphology was investigated using Atomic Force Microscope(AFM) in tapping mode configuration by a nanoscope III microscope, and Raman spectra were recorded in the $300-700 \mathrm{~cm}^{-1}$ range using a Jobin-Yvon spectrometer (T64000 model) equipped with an $\mathrm{Ar}^{+}$laser $(632.8 \mathrm{~nm}$ exciting line) and a CCD detector in a backscattering geometry. Transmittance spectra were recorded using a UV-vis spectrophotometer in the 350-1200 nm range. The reflectivity spectra of the $\mathrm{ZnO}$ thin films surfacewere measured using a LAMBDA $950 \mathrm{UV} / \mathrm{Vis} / \mathrm{NIR}$ spectrophotometer equipped with an integrating sphere. The composition of as-formed and treated $\mathrm{ZnO}$ thin film was analyzed by means of Fourier transform infrared spectroscopy (FTIR).The optical properties were analysed by photoluminescence technique PL) in the range 340-500 nm using a $299 \mathrm{~nm}$ line of an Ar laser as an excitation light source.

\section{RESULTS AND DISCUSSION}

\subsection{Structural properties}

Fig. 1 Demonstrates the XRD patterns of $\mathrm{ZnO}$ thin films for different zinc nitrate precursors. The films are polycrystallines with hexagonal Wurtzite structure and no parasite phase is observed. All the graphs of $\mathrm{ZnO}$ thin films shown a orientation along the (002) so the c-axis of the crystallites is perpendicular to the substrates, due to the minimization of internal stress and surface free energy [5,17].

By increasing the molar concentration of precursors, the intensity of preferential orientation was increased indicating that the films crystallinity has been improved, small peaks of (001) and (101) orientation also appeared in concentration 0.15 and $0.2 \mathrm{M}$.

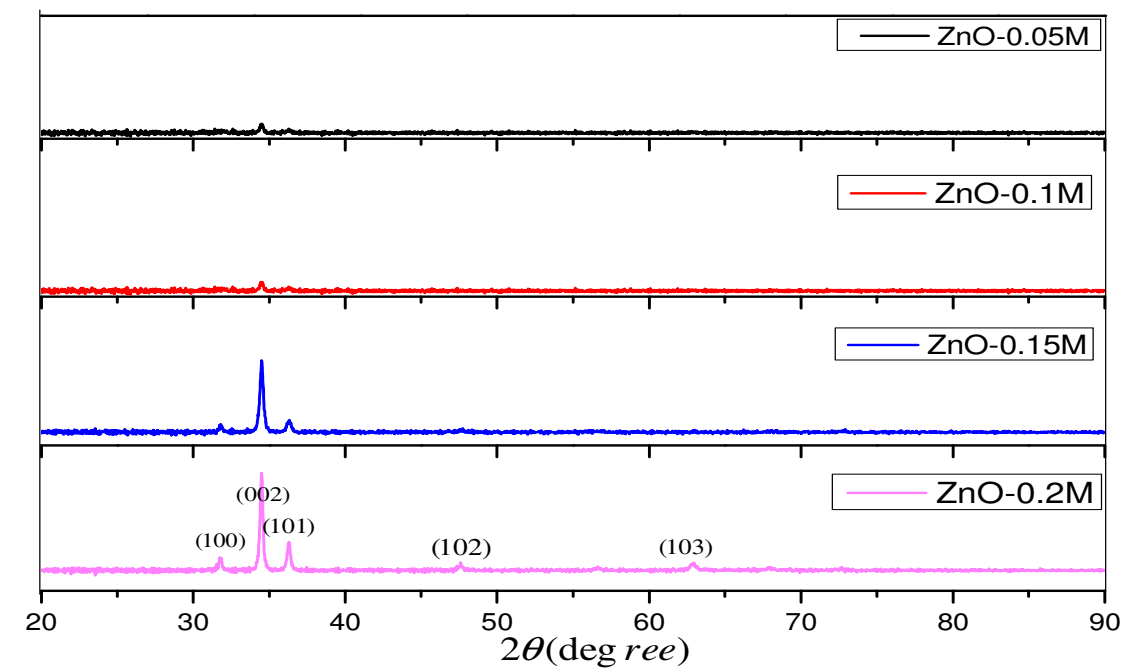

Figure 1: XRD patterns of $\mathrm{ZnO}$ films prepared with different molar concentration of precursor 
The crystallite size was calculated from the (002) diffraction peak using Scherer formula:

$\mathrm{D}=\frac{0.9 \lambda}{\beta \cos \theta}(1)$

$\mathrm{D}$ is the grain size in a particular orientation, $\lambda$ is the $\mathrm{X}$-ray wavelength, $\theta$ is the diffraction angle corresponding to the particular orientation, $\beta$ is the width at half maximum intensity (FWHM) of the peak.

Table 1 shows the evolution of particle size with the molarity. The results indicated that the crystal quality of $\mathrm{ZnO}$ thin film was significantly improved with the increasing in molar concentration.

We could have more crystal quality information by use this formula [18]:

$\delta=\frac{1}{\mathrm{D}^{2}}(2)$

With $\mathrm{D}$ is the average grain size. The dislocation density is the length of dislocation lines per unit volume of the crystal. Larger D and smaller $\delta$ values mean better crystallization of the films. Dislocation densities exhibit a decrease with increasing molar concentration, which indicates that the high molar concentration reduced the crystal lattice imperfections. The calculated $\mathrm{c}$ parameters were found to be $0.5211,0.5201,0.5198$, and $0.5195 \mathrm{~nm}$ when the molar concentration varied from $0.05 \mathrm{M}$ to $0.2 \mathrm{M}$, compared to 0.5206 for a powder sample. The $\mathrm{c}$ parameter values decrease with molar concentration. This defect is related to the stress increases in the plane of the substrate surface.

The stress in the plane of the substrate surface, the c-axis strain $\left(\varepsilon_{\mathrm{zz}}\right)$ values has been calculated using the following equation [19]:

$\varepsilon_{z z}=\frac{c-c_{0}}{c_{0}} \times 100$.

where $\mathrm{c}$ is the lattice parameter of the strained films calculated from the $\mathrm{X}$ ray diffraction data and $\mathrm{c}_{0}$ is the lattice parameter of bulk $\mathrm{ZnO}$. Figure 2 shows the evolution of strain against the molar concentration $(\mathrm{C})$. The strain is reduced when $\mathrm{C}$ increases.

For $0.05 \mathrm{M}$ the stress becomes positive $\left(\varepsilon_{\mathrm{zz}}>0\right)$ suggesting that the film is subjected to tensile stress in the plane of the substrate surface, and to compressive stress for the $0.1 \mathrm{M}, 0.15 \mathrm{M}$ and $0.2 \mathrm{M}$ concentrate samples.

Table 1: The particle size and dislocation with different precursor concentrations

\begin{tabular}{|c|c|c|c|c|}
\hline $\begin{array}{c}\text { Molar } \\
\text { concentration } \\
(\mathrm{M})\end{array}$ & $\begin{array}{c}2 \theta \\
(\text { degree }) \\
\text { of (002) }\end{array}$ & $\begin{array}{c}\text { FWHM } \\
(\text { degree })\end{array}$ & $\begin{array}{c}\text { Crystallite } \\
\text { size D } \\
(\mathrm{nm})\end{array}$ & $\begin{array}{c}\delta \times 10^{-3} \\
\left(\mathrm{~nm}^{-2}\right)\end{array}$ \\
\hline 0.05 & 34.40 & 0.82 & 9.95 & 10,1007 \\
\hline 0.1 & 34.47 & 0.30 & 27.40 & 1,3319 \\
\hline 0.2 & 34.51 & 0.25 & 32.35 & 0,9496 \\
\hline
\end{tabular}


In thin films, strains originate mainly from the mismatch between the polycrystalline film and the amorphous substrate and/or from the difference in the thermal expansion coefficients of the film and the substrate [20] The external stress parallel to surface of film were calculated from the DRX results using the following equation [21]:

$$
\sigma=\left(2 \mathrm{C}_{13}^{2}-\frac{\left(\mathrm{C}_{11}+\mathrm{C}_{12}\right) \mathrm{C}_{33}}{2 \mathrm{C}_{13}}\right) \varepsilon_{\mathrm{zz}}
$$

Where Cii are the elastic constants of $\mathrm{ZnO}$ bulk, its values are;

$\mathrm{C}_{11}=208.8 \mathrm{GPa}, \mathrm{C}_{12}=119.7 \mathrm{GPa}, \mathrm{C}_{13}=104.2 \mathrm{GPa}, \mathrm{C}_{33}^{\text {couche }}=213.8 \mathrm{GPa}$.

Table 2 shows the external stress with different molar concentrations. At $0.05 \mathrm{M}$ the external stress was compressive, and became tensile for the three other concentrations, indicating a relaxation of the structure with the increase of the grain's size.

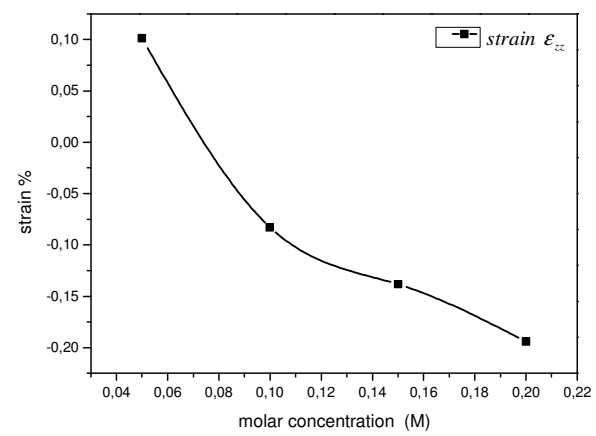

Figure 2: Evolution of strain vs the molar concentration

\begin{tabular}{|c|l|}
\hline $\begin{array}{l}\text { Molar } \\
\text { concentration(M) }\end{array}$ & $\sigma(\mathrm{GPa})$ \\
\hline 0.05 & $-23,6077906$ \\
\hline 0.1 & 19,31523402 \\
\hline 0.15 & 32,25406444 \\
\hline 0.2 & 45,28236113 \\
\hline
\end{tabular}

Table 2: The external stress with different precursor concentrations

\subsection{Morphological properties.}

Fig 3 and 4 show the evolution of the grain size and the 2D. AFM surface morphology as a function of Figure 3 shows that increasing concentration influences the size grain. The grain present the spheres shape with uniform and homogenous distribution on the surface. It when increasing the molarity, a more random distribution of the grains on the surface is observed, which lead to a higher roughness. It is also observed that the particles agglomerated to form a porous structure.

The size measures of the particles from the AFM surface images are $13.3 \mathrm{~nm}, 21.5 \mathrm{~nm}, 44.9 \mathrm{~nm}$ for molar concentration $0.05,0.1$ and $0.2 \mathrm{M}$ respectively. These values are higher than the values 
calculated from XRD data. This could be explained by the fact that XRD data is an average over a large area $\left(\right.$ few $\left.\mathrm{mm}^{2}\right)$, where AFM gives information about a micrometric area.

Fig 5 shows the AFM images 3D of $\mathrm{ZnO}$ thin films, the grains are orthogonal to the film surface indicating that the film grows perpendicularly to the substrate. The fig 6 shows the average surface roughness (Rms). The Rms varies from $8.34 \mathrm{~nm}$ to $20.54 \mathrm{~nm}$ when molar concentration increases from $0.05 \mathrm{M}$ to $0.2 \mathrm{M}$. This evolution of the surface roughness is as a result of the grain size increasing.

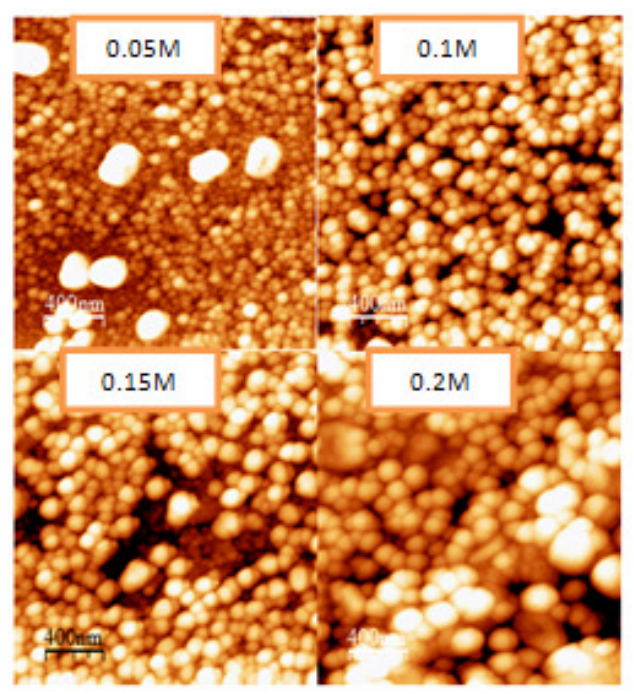

Figure3: AFM images 2D of $\mathrm{ZnO}$ thin film in different molar concentration

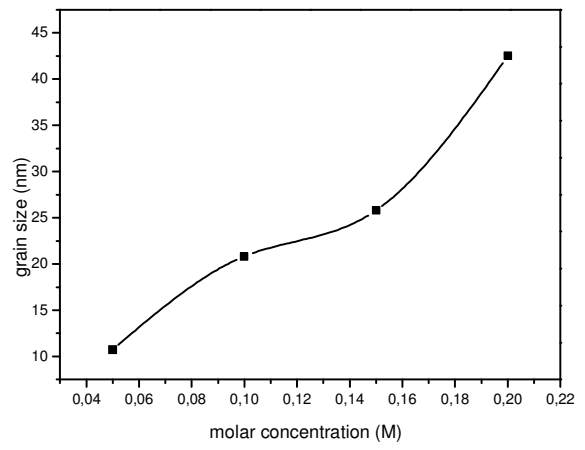

Figure 4: Evolution of the grain size against the molar concentration 
Advanced Energy: An International Journal (AEIJ), Vol. 2, No. 4, October 2015
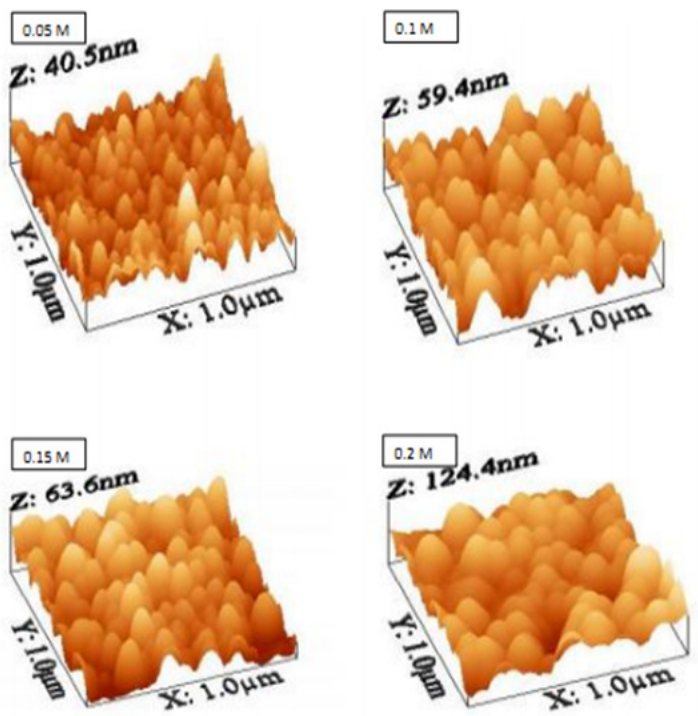

Figure 1: The AFM images 3D of $\mathrm{ZnO}$ thin films in different molar concentration

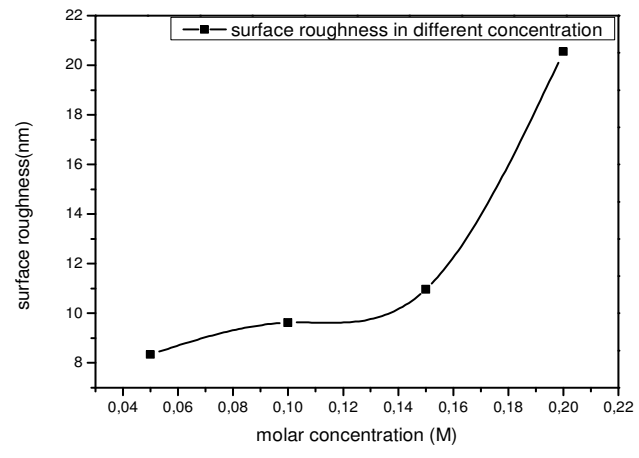

Figure 6: Evolution of RMS according the molar concentration

\subsection{FTIR}

The FTIR analysis of $\mathrm{ZnO}$ thin film is shown in fig 7.The shoulder observed at $3556 \mathrm{~cm}^{-1}$ in all samples corresponds to the $\mathrm{O}-\mathrm{H}$ moiety emanating from water [22].The very smalls peak for $\mathrm{N}-\mathrm{H}$ stretching at $2940 \mathrm{~cm}^{-1}$ and $2450 \mathrm{~cm}^{-1}$. The last peak illustrates the $\mathrm{Zn}-\mathrm{O}$ at $500-400 \mathrm{~cm}^{-1}$ [23].

\subsection{Raman}

Raman spectra of the films were taken in order to confirm the presence of the Wurtzite phase in the $\mathrm{ZnO}$ thin films.

$\mathrm{ZnO}$ in the hexagonal structures with $\mathrm{C}_{6 \mathrm{v}}^{4}$ symmetry each unit cell has 4 atoms and occupies $2 \mathrm{~b}$ sites of symmetry. The group theory predicts eight sets of phonon normal modes at the $\Gamma$ point, namely, $1 \mathrm{~A} 1+1 \mathrm{E} 1+2 \mathrm{~B} 1+2 \mathrm{E} 2[24]$. 
Advanced Energy: An International Journal (AEIJ), Vol. 2, No. 4, October 2015

Figure 8 shows a dominate mode centered at $437 \mathrm{~cm}^{-1}$ which shifted to , the red shift $\left(2 \mathrm{~cm}^{-1}\right)$ for molar concentration of $0.15 \mathrm{M}$. All samples present a peak with strong intensity corresponding to E2 $(\mathrm{H})[25], \mathrm{E} 2(\mathrm{H})$ mode involving mainly $\mathrm{Zn}$ motion, which corresponds to band characteristic of Wurtzite phase the lowest E1(LO) for all the sample appears around 582 $\mathrm{cm}^{-1}$. The high intensity of the E2 mode and lowest E1 (LO) mode indicate the higher quality of crystal in different concentrations.

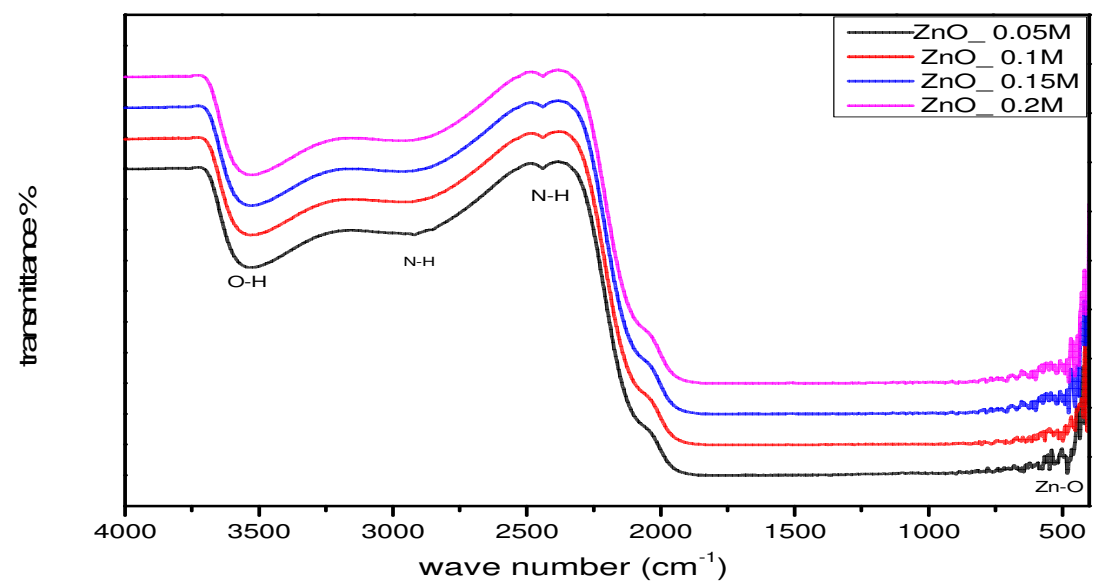

Figure7: The FTIR analysis of $\mathrm{ZnO}$ thin film synthesized with different molar concentrations

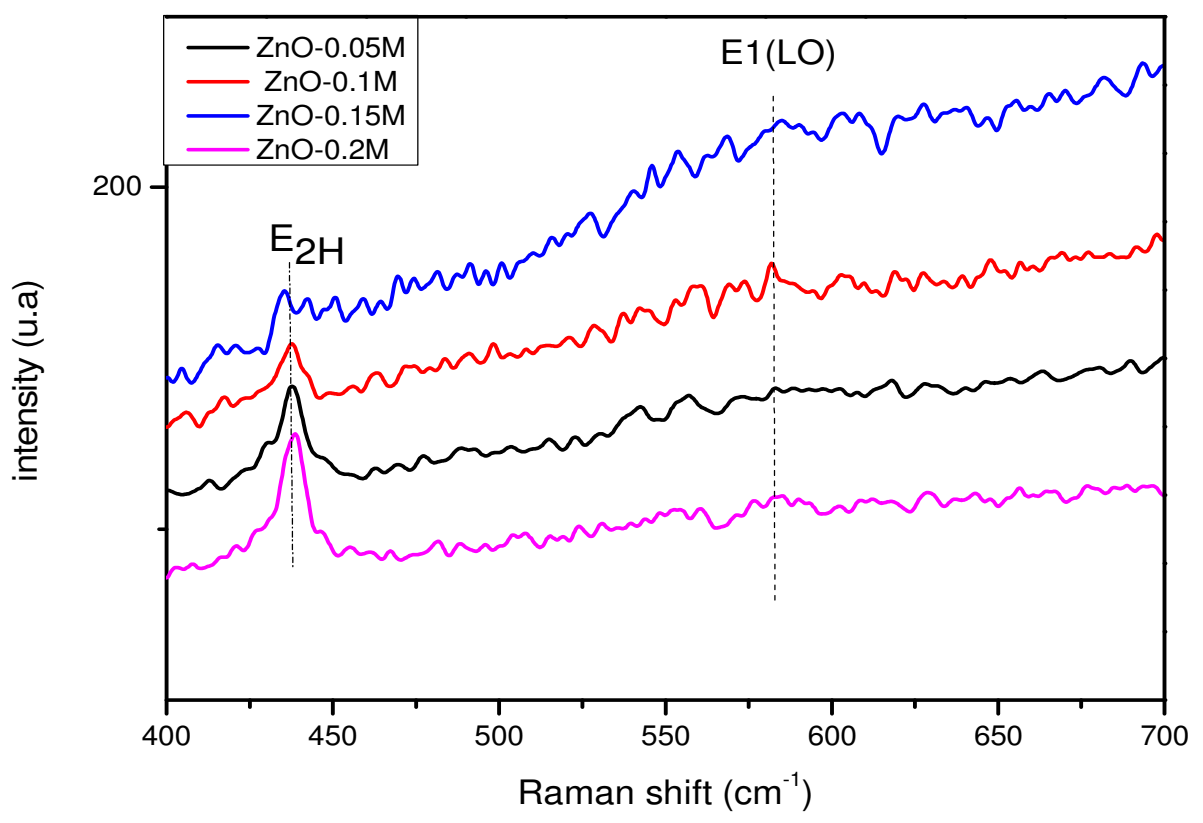

Figure 8: Raman spectra of $\mathrm{ZnO}$ prepared by spray pyrolysis with different molar concentrations 


\subsection{Optical properties.}

\subsubsection{Transmission}

The optical transmission curves of $\mathrm{ZnO}$ thin films recorded as a function of wavelength in the range of $200 \mathrm{~nm}$ to $1200 \mathrm{~nm}$ are shown in fig9.

All the films are mostly transparent in the visible region. However, the transmission goes down from $93 \%$ to $73 \%$ when the concentration increased from $0.05 \mathrm{M}$ to $0.2 \mathrm{M}$.All the films are highly absorbent in UV. The reduction of transmittance at higher molar concentration may be attributed to the increased scattering of photons by increase of the roughness of the surface morphology.

All the samples show a sharp absorption edge near to $375 \mathrm{~nm}$ in the UV region. This absorption edge was found to have a red shift when increasing the molarity.

The optical band gap was determined using method of Tauc [26];

$(\mathrm{ah} v)^{2}=\mathrm{C}(\mathrm{h} v-\mathrm{Eg}),(5)$

$\mathrm{C}$ is a constant; $\mathrm{h} v$ is the photon energy and Eg is the optical band gap. The optical absorption coefficient (a) was calculated using the following equation:

$\mathrm{a}=-\frac{\ln (\mathrm{T})}{\mathrm{D}}$

were the normalized transmission $\mathrm{T}$ was obtained from optical transmission spectra which has been normalized to the highest measured values by setting it to $100 \%, \mathrm{D}$ the diameters values of the crystal

Table 3 shows the values of the energy band gap of $\mathrm{ZnO}$ thin films grows in different molar concentration of precursors.

The value of the optical band gap is obtained by linearly extrapolating the linear portion to $a=0$.

With increasing in molar concentration from $0.05 \mathrm{M}$ to $0.2 \mathrm{M}$ the energy band gap decreased from 3,64 to $3,16 \mathrm{eV}$, the decreased in band gap energy with increasing in molar concentration could be due to increase in carrier concentration and decrease in strain values. It has been demonstrated earlier the correlation between the direct band gap and the compressive stress of the $\mathrm{ZnO}$ thin films [27]. 
Advanced Energy: An International Journal (AEIJ), Vol. 2, No. 4, October 2015

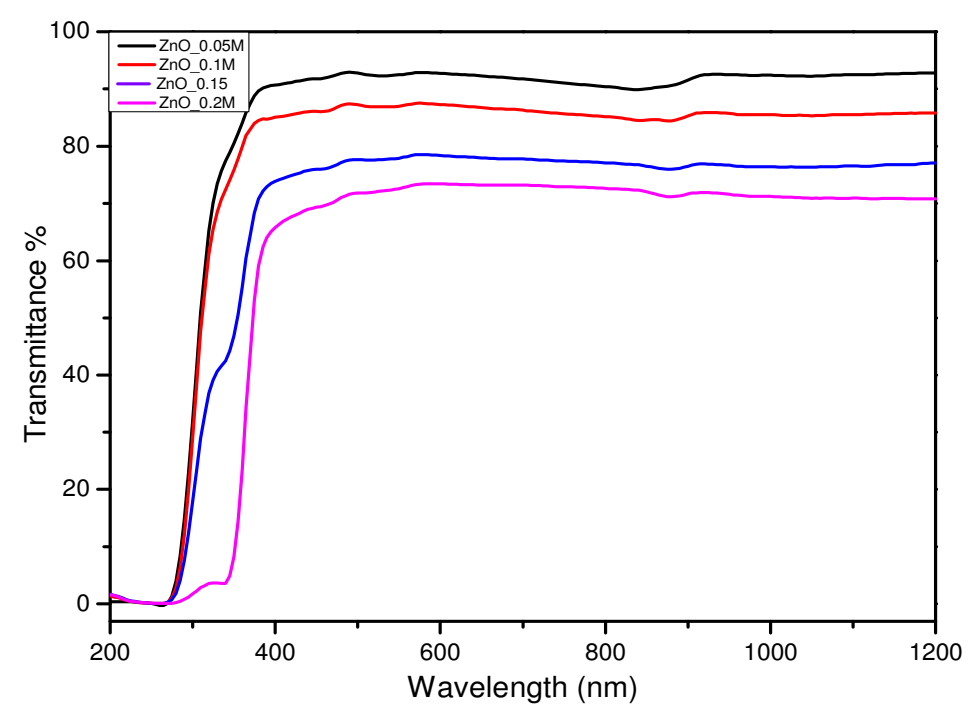

Figure 9:Transmission spectra with different molar concentrations

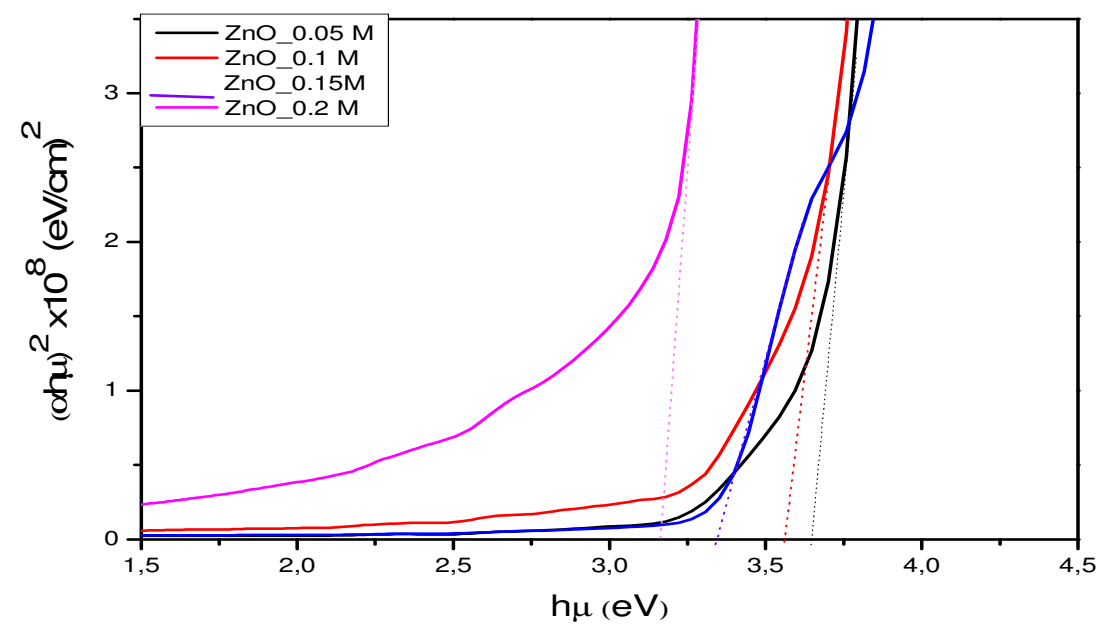

Figure 10: $(\alpha h v)^{2} \mathrm{vs}$ hv plot of thin film with different molar concentrations

Table 3: Energy band gap in different molar concentration

\begin{tabular}{|l|l|l|l|l|}
\hline $\begin{array}{l}\text { Samplesmolar } \\
\text { concentration }(\mathrm{M})\end{array}$ & 0.05 & 0.1 & 0.15 & 0.2 \\
\hline Eg $(\mathrm{eV})$ & 3.64 & 3.56 & 3.34 & 3.15 \\
\hline
\end{tabular}




\subsubsection{Reflectance}

These spectra show the excellent antireflection properties of the $\mathrm{ZnO} / \mathrm{Glass}$ layer with different concentrations (fig 11). The total reflectivity had a low values in lower molar concentrations due to a lower values of RMS in the lower molar concentration this values increasing from $10 \%$ to $12 \%$. Obviously, the increase of surface roughness causes the increase in scattering, reflection on the film surface[28], and thus the transmittance of the film decreases.

\subsection{Photoluminescence proprieties.}

PL spectra of $\mathrm{ZnO}$ thin films are shown in fig 12. It is clearly seen that the photoluminescence intensity depends strongly on the molar concentration of precursor.

It shows a very intense emission peaks around $378 \mathrm{~nm}$, the UV emission has been claimed to be due the near-band edge emission NBE or recombination of free exciton-exciton collision process[29], the intensity of this peaks was increased with the molar concentration, also the weak peaks appears in $432 \mathrm{~nm}$ only in the lower precursors concentration $0.05 \mathrm{M}$ and $0.1 \mathrm{M}$ attributed of the presence of defects in this films, this results confirm the next results obtained in DRX spectra, and RAMAN spectra, when the improvement of the quality the crystal is investigated with the increasing of precursor concentration.

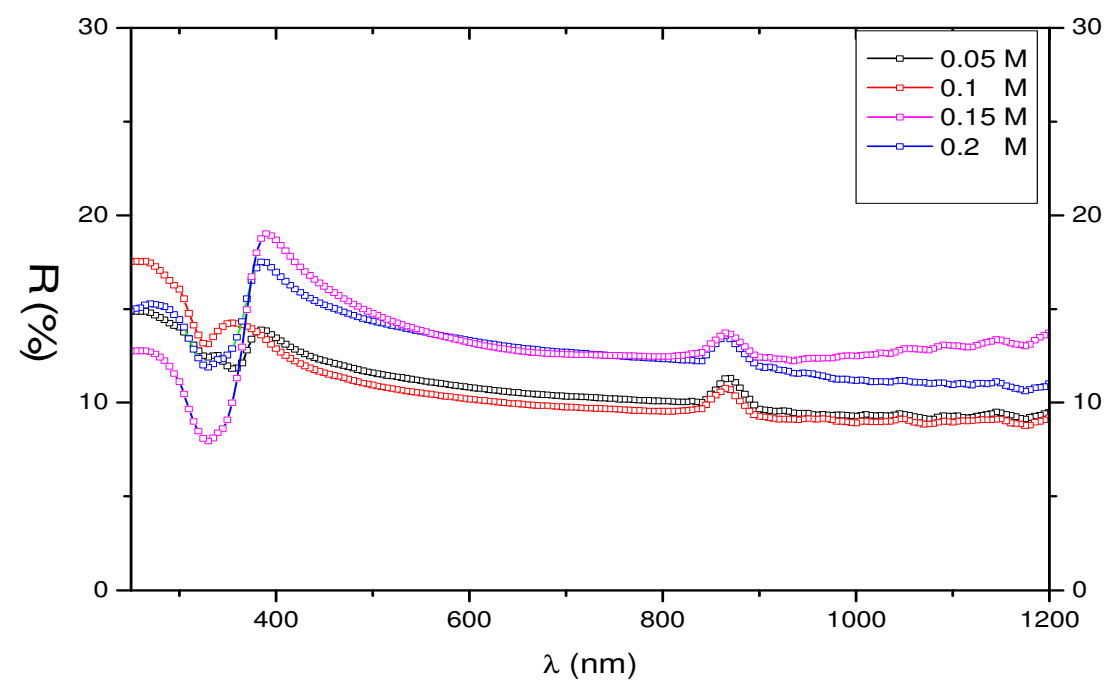

Figure 11:Total reflectivity of $\mathrm{ZnO}$ thin film growth in different molar concentrations 


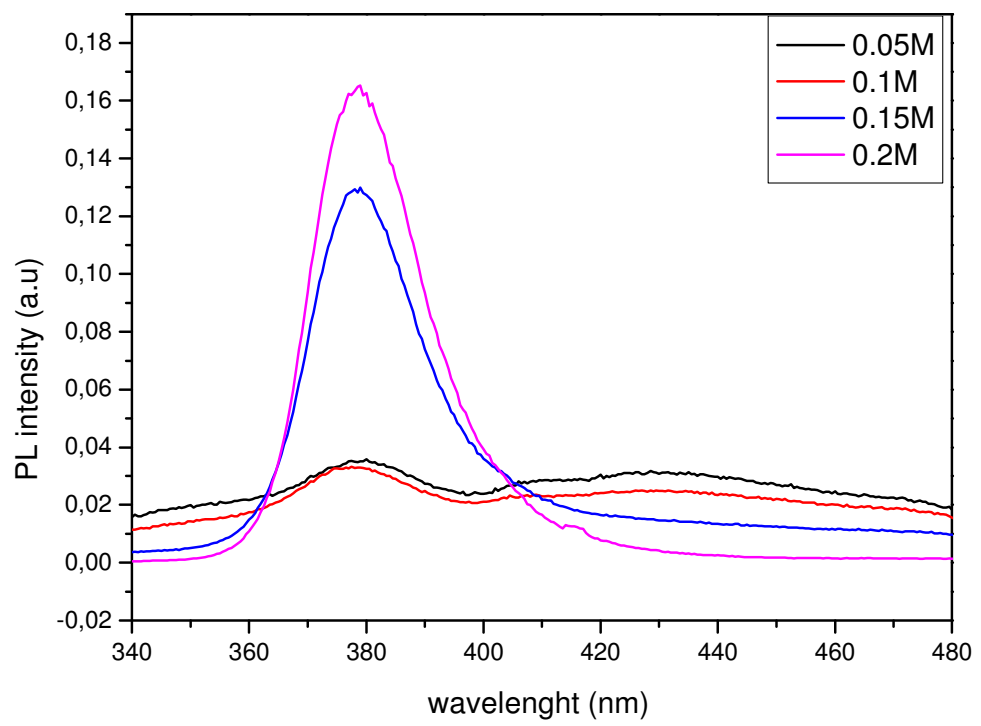

Figure 12: The PL spectrum of the $\mathrm{ZnO}$ thin film

\section{CONCLUSION}

In the present work, $\mathrm{ZnO}$ thin films were deposited by a simple and cheap deposition technique, namely spray pyrolysis. The X-ray diffraction showed that films have a polycrystalline structure with an orientation according to the c-axis corresponding to the (002) crystallographic orientation. The intensity of this peak and grain size were increasing, With the increase in molar concentration .The Raman result confirms the high quality of the crystal. The FTIR shows the existence of the $\mathrm{Zn}-\mathrm{O}$ band between $500-400 \mathrm{~cm}^{-1}$ and the $\mathrm{O}-\mathrm{H}$ moiety emanating from water in $3556 \mathrm{~cm}^{-1}$.

The optical measurements have shown a decrease in the transmission $\mathrm{T}(\%)$ with an increase in the molarity dueto the surface roughness. The band gap values were decreased from $3.64 \mathrm{eV}$ to $3.15 \mathrm{eV}$ as molarity of the solution increased for $0.05 \mathrm{M}$ to $0.2 \mathrm{M}$. The main results are a decrease of surface reflectivity from $12 \%$ to about $10 \%$.

The PL spectra have shown the existence of different defects in the visible range of $\mathrm{ZnO}$ thin film of the lower molar concentration $0.05 \mathrm{M}$ and 0.1M.RAMAN spectra confirm the progress of the quality of the films in the higher precursor concentration $0.15 \mathrm{M}$ and $0.2 \mathrm{M}$.

\section{ACKNOWLEDGMENT}

This work was carried out with support from the Tunisian Ministry of Higher Education and Scientific Research and in the framework of the scientific cooperation Tunisian - Moroccan (CMPTM) 


\section{REFERENCES}

[1] M. Belarbi, A.Benyoucef , B. Benyoucef (2014) "simulation of the solar cells with PC1D, application to cells based on silicon" advanced Energy :An international journal, vol 1 ,No.3.

[2] M. Belarbi, A.Benyoucef , B. Benyoucef(2014)"study of the equivalent circuit of a dye- sensitized solar cells" advanced Energy :An international journal, vol 1 ,No.2.

[3] Babar Hussain , Abasifreke Ebong, Ian Ferguson (2015)“Zinc oxide as an active n-layer and antireflection coating for silicon based heterojunction solar cell” Solar Energy Materials \& Solar Cells 139 p 95-100

[4] Long Yang, Bao-gai Zhai, Qing-lan Ma, Yuan Ming Huang , (2014)"Effect of ZnO decoration on the photovoltaic performance of $\mathrm{TiO} 2$ based dye sensitized solar cells,"Journal of Alloys and Compounds 605 109-112.

[5] Mazabalo Baneto, Alexandru Enesca, Yendoubé Lare, Koffi Jondo, Kossi Napo, Anca Duta, (2014)"Effect of precursor concentration on structural, morphological and opto-electric properties of $\mathrm{ZnO}$ thin films prepared by spray pyrolysis,"Ceramics International,40 8397-8404.

[6] Brijesh Kumar, Sang-Woo Kim, (2012)"Energy harvesting based on semiconducting piezoelectric ZnO nanostructures",Nano Energy 1, 342-355.

[7] Daqiang Gao, Zhaohui Zhang, Junli Fu, Yan Xu, Jing Qi and Desheng Xue, (2009)"Room temperature ferromagnetisof pure ZnO nanoparticles“,J. Appl. Phys. 105, 113928 .

[8] A.J. Behan, J.R. Neal, R.M. Ibrahim, A. Mokhtari, M. Ziese, H.J. Blythe, A.M. Fox and G.A. Gehring, (2007)"Magneto-optical and transport studies of ZnO-based dilute magnetic semiconductors," Journal of Magnetism and Magnetic Materials 310, 2158

[9] B. El Idrissi, M. Addou, A. Outzourhit, M. Regragui, A. Bougrine, A. Kachouane , (2001) "Sprayed $\mathrm{CeO} 2$ thin films for electrochromic, applications Solar Energy Materials \& Solar Cells 69 1-8 .

[10] C. Besleaga, G.E. Stan, A.C. Galca, L. Ion, S. Antohe, (2012)"Double layer structure of ZnO thin films deposited by RF-magnetron sputtering,"on glass substrate Applied Surface Science 2588819 8824.

[11] K. Bab, C. Lazzaroni, O. Brinza, M. Nikravech, (2014)"Effect of zinc nitrate concentration on structural and optical properties of $\mathrm{ZnO}$ thin films deposited by Spray Plasma device," Thin Solid Films 558 62-66.

[12] Zi-Neng Ng, Kah-Yoong Chan, Thanaporn Tohsophon, (2012) "Effects of annealing temperature on ZnO and AZO films prepared by sol-gel technique",Applied Surface Science 258 9604-9609.

[13] L. Moreno, C. Sánchez-Aké, M. Bizarro, (2014)”Double-beam pulsed laser deposition for the growth of Al-incorporated ZnO thin films". Applied Surface Science 302 46-51.

[14] E. Bacaksiz, M. Parlak, M. Tomakin , A. Ozcelik a, M. Karakız , M. Altunbas , (2008) Journal of Alloys and Compounds 466 447-450

[15] E. U. Masumdar and M. A. Barote, (2013)" The effects of zinc nitrate, zinc acetate and zinc chloride precursors oninvestigation of structural and optical properties of $\mathrm{ZnO}$ thin films," Journal of Chemical, Biological and Physical Sciences, 3 525-533.

[16] B. Elidrissi, M. Addou, M. Regragui, A. Bougrine, (1998) Lebanese Sci. Res. Rep. 3 (4) 230

[17] Norifumi Fujimura, Tokihiro Nishihara, Seiki Goto, Jifang Xu and Taichiro lto(1993),"control of pereffed oriention for ZnOxfilms :control of self -textutre," Journal of Crystal Growth 130 269-279.

[18] L. Yang ,B. Duponchel , R. Cousin , C. Gennequin , G. Leroy , J. Gest , J.-C. Carru , (2012)"Structure, morphology and electrical characterizations of direct current sputtered $\mathrm{ZnO}$ thin films," $5204712-4716$.

[19] M. Babar Shahzad, Yang Qi ,Hong Lu, Xiandi Wang, (2013)"A study on the Al doping behavior with sol aging time and its effect on structural and optical properties of sol-gel prepared $\mathrm{ZnO}$ thin films Thin Solid Films,"534 242-248. [20] R. Swapn, M. Ashok, G. Muralidharan, M.C. Santhosh Kumar, (2013) "Microstructural, electrical and optical properties of $\mathrm{ZnO}$ :Mo thin films with various thickness by spray pyrolysis",Journal of Analytical and Applied Pyrolysis 102 68-75

[21] Min Su Kim, Soaram Kim, Giwoong Nam, Dong-Yul Lee, Jae-Young Leem, (2012)"Effects of buffer layer thickness on properties of $\mathrm{ZnO}$ thin films grown on poroussilicon by plasma-assisted molecular beam epitaxy", Optical Materials 34 1543-1548

[22] K. Raja, P.S. Rameshb, D. Geetha, (2014)"Structural, FTIR and photoluminescence studies of Fe dopedZnO nanopowder by co-precipitation method",Spectrochimica Acta Part A: Molecular and Biomolecular Spectroscopy 131 183-188. 
[23] Muneer M. Ba-Abbad, Abdul Amir H. Kadhum, Abu Bakar Mohamad, Mohd S. Takriff ,Kamaruzzaman Sopian, (2013) "The effect of process parameters on the size of ZnO nanoparticles synthesized via the sol-gel technique",Journal of Alloys and Compounds 550 63-70.

[24] S. Ben Yahiaa, L. Znaidia, A. Kanaeva, J.P. Petitet, (2008)"Raman study of oriented ZnO thin films deposited by sol-gel method,"Spectrochimica Acta Part A 71 1234-1238

[25] O. Karzazi, A. Chahboun, A.G. Rolo, E.K. Hlil, N. Benzakour, K. Bouslykhane, A.Hourmatallah,S. Levichev, A. Khodorov, and M.J.M. Gomes , (2010)"Study of the substitution effect of Mn doped in ZnO matrix,” Eur. Phys. J. Appl. Phys. 50, 30801.

[26] Hamdan Hadi Kusuma, Mohamad Khairi Saidin, Zuhairi Ibrahim, (2009)"OPTICAL PROPERTIES OF Ti:A12O3 SINGLE CRYSTAL”, J. Fiz. UTM. Vol. 4. 42-49.

[27] B.L. Zhu, J. Wang , S.J. Zhu , J. Wu , D.W. Zeng , C.S. Xie, (2012) “Optimization of sputtering parameters for deposition of Al-doped $\mathrm{ZnO}$ films by rfmagnetron sputtering in $\mathrm{Ar}+\mathrm{H} 2$ ambient at room temperature,"Thin Solid Films 520 6963-6969

[28] M. Salem , Z. Yamlahi Alami , B. Bessais ,A. Chahboun ,M. Gaidi, (2015)”Structural and optical properties of $\mathrm{ZnO}$ nanoparticles deposited on porous silicon for mc-Si passivation”, J Nanopart Res, $17: 13$

[29] Nurul Izni Rusli, Masahiro Tanikawa , Mohamad Rusop Mahmood, Kanji Yasui 3 andAbdul Manaf Hashim, (2012) "Growth of High-Density Zinc Oxide Nanorods on Porous Silicon by Thermal Evaporation"Materials, 5, 2817-2832 